\title{
Produção de serapilheira e suas frações em área da Caatinga no Semiárido Tropical*
}

\author{
Matheus Magalhães Silva Moura ${ }^{1, \$}$, Geovane Barbosa Reinaldo Costa ${ }^{1}$, \\ Helba Araújo de Queiroz Palácio ${ }^{1}$, José Ribeiro de Araújo Neto², José \\ Bandeira Brasil ${ }^{2}$
}

${ }^{1}$ Instituto Federal do Ceará, Campus Iguatu. Vila Cajazeiras, S/N. Iguatu-CE (CEP 63500-000). ${ }^{\S}$ E-mail: matheusmsm@hotmail.com.br.

2Universidade Federal do Ceará. Departamento de Engenharia Agrícola. Campus do PICI. Bloco 804. Fortaleza-CE (CEP 60450-760).

Resumo. Para avaliar a deposição da serapilheira e as frações folhas, galhos, estruturas reprodutivas e miscelânea em área da Caatinga Nativa, bem como, verificar a interferência de variáveis climáticas, desenvolveu-se um estudo em uma microbacia experimental localizada no Município de Iguatu, Ceará, Brasil. A produção de serapilheira foi coletada mensalmente, entre os meses de abril de 2013 a março de 2014. Para a quantificação da serapilheira depositada sobre o solo da Caatinga, foram instaladas 20 caixas coletoras na área estudada, construídas de madeira, com dimensões de 1,0 m x 1,0 m x $0,2 \mathrm{~m}$. Separando-se em seguida as frações de folhas, estruturas reprodutivas, galhos e miscelânea. A produção de folhas apresentou uma estreita relação com o regime pluviométrico, sendo seu ápice logo após a quadra chuvosa, enquanto a produção de estruturas reprodutivas foi determinada pelas espécies. A produção da serapilheira foi estimada em 4.038,79 $\mathrm{kg} \mathrm{ha}^{-1}$, a fração folha apresentou maior contribuição com $1.268,57 \mathrm{~kg} \mathrm{ha}^{-1}$. A maior deposição ocorreu na estação seca, onde a floresta Caatinga perde sua folhagem como estratégia de adaptação as condições climáticas semiáridas. A serapilheira estocada apresentou maior acumulo no período seco (verão) onde a fração folha apresentou o maior acumulo.

Palavras-chave: Deposição; Folhas; Miscelânea; Microbacia.

Abstract. Burlap production and their functions in Caatinga area in Tropical Semiarid. To evaluate the deposition of litter and its fractions leaves, twigs reproductive structures and miscellany in the area of Caatinga Native as well, check the interference of climatic variables, we developed a study in an experimental catchment located in the Municipality of Iguatu, Ceará, Brazil. Litter production was collected monthly between the months of April 2013 to March 2014. For quantification of litter deposited on the soil of Caatinga, they were installed 20 collection boxes in the study area, built of wood, with dimensions of $1.0 \mathrm{~m} \times 1.0 \mathrm{~m} \times 0.2 \mathrm{~m}$. Separating then the fractions leaves, reproductive structures, branches and miscellany. The leaf production had a close relationship with the rainfall regime,
Recebido:

29/07/2016

Aceito:

29/09/2016

Publicado:

30/09/2016

Acesso Aberto

Artigo completo

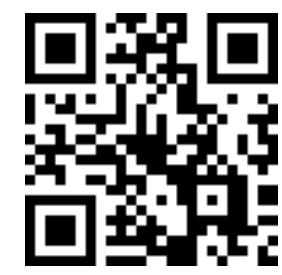

ORCID

(ㄷ) 0000-0001-5460-3198

Matheus Magalhães

Silva Moura

(1) 0000-0002-1442-8273

Geovane Barbosa

Reinaldo Costa

(D) 0000-0002-5105-4821

Helba Araújo de

Queiroz Palácio

(1) 0000-0001-7118-1644

José Ribeiro de Araújo

Neto

D 0000-0003-4335-7838

José Bandeira Brasil

\footnotetext{
*Apresentado no V Congresso Brasileiro de Educação Ambiental Aplicada e Gestão Territorial, Fortaleza/CE, 8 a 11/06/2016.
} 
with its peak just after the rainy season, while the production of reproductive structures was determined by the species. The production of litter was estimated at 4,038.79 $\mathrm{kg} \mathrm{ha}^{-1}$, the leaf fraction showed greater contribution to $1,268.57 \mathrm{~kg} \mathrm{ha}^{-1}$. The higher deposition occurred in the dry season, where the Caatinga forest loses its leaves as an adaptation strategy the semi-arid climatic conditions. The lunge litter showed higher accumulation in the dry season (summer) where the leaf fraction showed the highest accumulation.

Keywords: Deposition; Sheets; Miscellany; Microbasin.

\section{Introdução}

A Caatinga é o bioma mais extenso da região Nordeste brasileiro, ocupando área de $844,453 \mathrm{~km}^{2}$ ou $11 \%$ do território nacional (MMA, 2014). A Região da Caatinga é o bioma menos estudado e protegido entre todos os biomas brasileiros. Entender o funcionamento e as variáveis que promovem maior ou menor estabilidade a uma comunidade vegetal e/ou animal é essencial para que se possa intervir sem, no entanto, degradá-la. A deposição e decomposição de serapilheira em ambientes florestais é a principal via de transferência no fluxo de nutrientes, sendo fundamental para a sustentabilidade dessas comunidades entre outras coisas.

$$
\mathrm{Na} \quad \text { Região Nordeste, }
$$
particularmente em área de Caatinga, os aspectos relacionados com o fluxo de deposição de serapilheira, as interações do processo com parâmetros climáticos e edáficos não tem sido estudados, apesar da importância do assunto em relação a este tipo de vegetação, principalmente no que se refere às condições físicas do solo, como a melhoria da estrutura, retenção de umidade, aumento da aeração e redução do processo erosivo (Santana, 2005). A serapilheira que cai das árvores nesse ecossistema protege o solo na estação seca quando as temperaturas são mais elevadas, mas, logo que chegam as primeiras chuvas, parte dela é degradada pelos microrganismos decompositores, não ocorrendo grande acúmulo de material orgânico na superfície (Souto, 2006).

A serapilheira, em uma floresta, é a principal via de transferência no fluxo de nutrientes, e fundamental para a sua sustentabilidade, uma vez que permite que boa parte dos 16 nutrientes absorvidos pelas plantas retorne ao solo para serem novamente assimilados. Sua composição se faz pela deposição de materiais vegetais na superfície do solo, tais como folhas, cascas, ramos, troncos, gravetos, flores, inflorescências, frutos, sementes e fragmentos vegetais não identificáveis, este último denominado miscelânea. A deposição da serapilheira introduz heterogeneidade temporal e espacial ao ambiente, podendo afetar a estrutura e a dinâmica da comunidade vegetal (Facelli e Pickett, 1991; Ferreira et al., 2007).

A serapilheira, entre outras funções, protege 0 solo contra as elevadas temperaturas, armazena em seu conteúdo uma grande quantidade de sementes prontas para germinar ou em estado de dormência, abriga uma abundante fauna composta por micro e macro invertebrados que atuam diretamente nos processos de decomposição desses materiais, fertilizando naturalmente os solos (Costa et al., 2007). Parte do processo de retorno de matéria orgânica e de nutrientes para o solo florestal se dá através da produção de serapilheira, sendo essa, considerada o meio mais importante de transferência de elementos essenciais da vegetação para o solo (Vital et al., 2004).

De acordo com Bray e Gorhan (1964 apud Alves et al., 2006), a quantidade de material depositado ao longo de um ano, em um determinado ecossistema, está relacionada principalmente com as condições climáticas, sendo menor nas regiões frias e maior nas regiões equatoriais quentes e úmidas. A serapilheira ajuda a minimizar os 
processos erosivos, também age como uma barreira que evita a intensa lixiviação pela ação das chuvas, retém considerável proporção de água, reduzindo a evaporação do solo.

O objetivo do trabalho é verificar o comportamento da serapilheira nos períodos secos e chuvosos, bem como compreender as frações estudadas e analisar a influência das precipitações nas respectivas frações: folhas, galhos, estrutura reprodutiva e miscelânea.

\section{Material e métodos}

$\mathrm{O}$ estudo foi conduzido na microbacia experimental nativa que possui aproximadamente 2,06 ha sua área e está localizada na Bacia Experimental de Iguatu (BEI) (Figura 1). Os solos predominantes da BEI são Neossolos Flúvicos, Neossolos Litólicos, Luvissolos, Vertissolos, Argissolos e Planossos Nátricos (FUNCEME, 2012). Especificamente na área estudada, o relevo é suave ondulado e apresenta solos rasos e pedregosos.

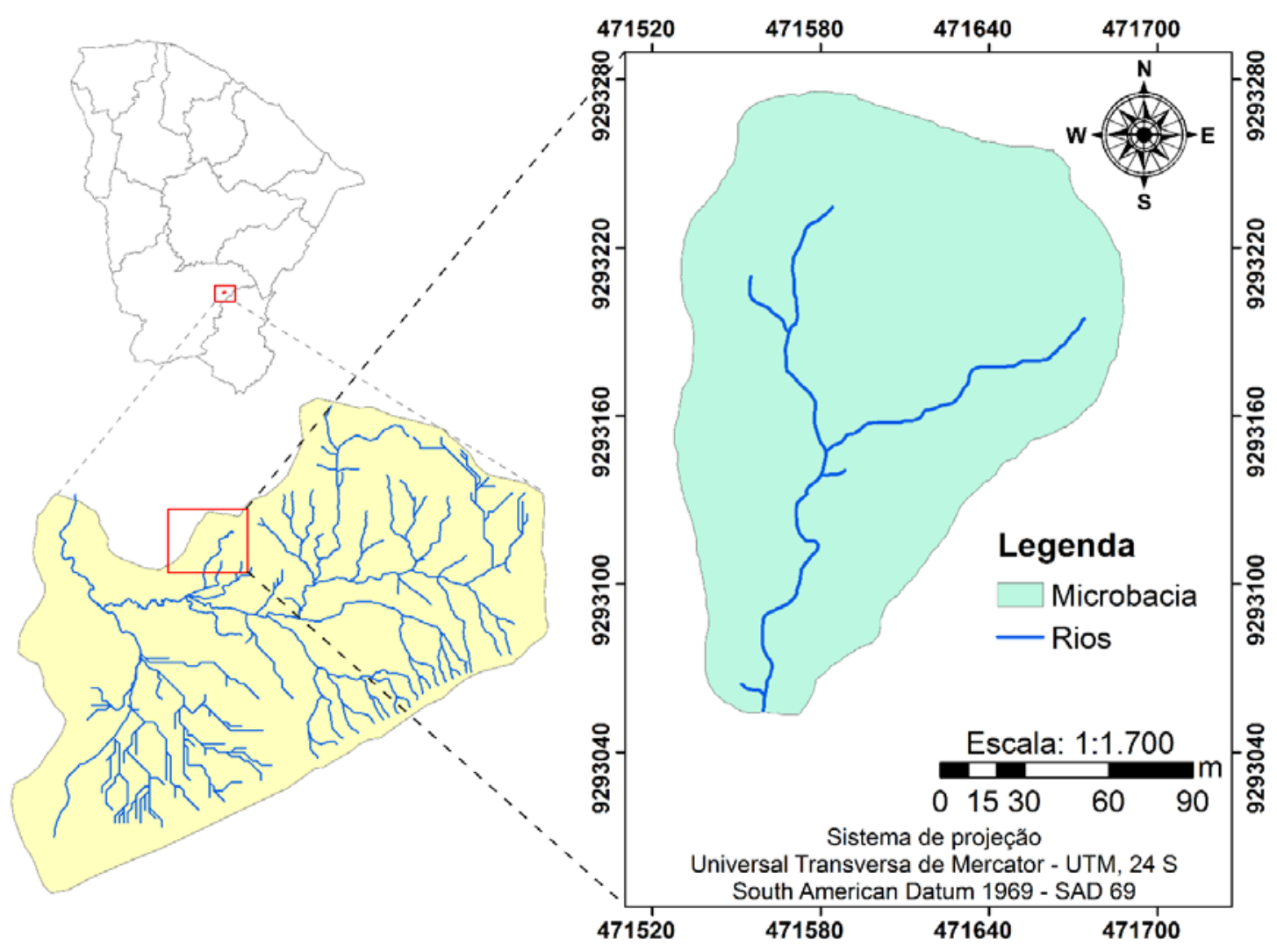

Figura 1. Microbacia em estudo localizada na Bacia Experimental de Iguatu, Ceará.

Tabela 1. Características climáticas para o Município de Iguatu, Ceará.

\begin{tabular}{lcc}
\hline Variável & Valor & Unidade \\
\hline Precipitação pluviométrica (1985-2014) & 1026,4 & $\mathrm{~mm} \mathrm{ano}^{-1}$ \\
Temperatura máxima média & 31,7 & ${ }^{\circ} \mathrm{C}$ \\
Temperatura mínima média & 20,3 & ${ }^{\circ} \mathrm{C}$ \\
Insolação & 2897,6 & $\mathrm{~h} \mathrm{ano}^{-1}$ \\
Umidade relativa do ar & 61,8 & $\%$ \\
\hline
\end{tabular}

Fonte: Santos (2012), Pinheiro (2015). 
O clima da região é do tipo BSw'h' (Semiárido quente), de acordo com a classificação climática de Köppen, com temperatura média sempre superior a $18{ }^{\circ} \mathrm{C}$ no mês mais frio. Observa-se que o período de (1985-2014) a média da Precipitação pluviométrica foi de $1.026,4 \mathrm{~mm}$ ano $^{-1}$ (Tabela 1). Já a média da temperatura máxima é $31,7^{\circ} \mathrm{C}$ e a mínima de $20,3^{\circ} \mathrm{C}$.

Uma das principais características da vegetação da caatinga é que grande parte das espécies perdem suas folhas durante a estação seca. É um recurso para diminuir a perda de água durante o período seco. Muitas espécies vegetais estocam água no caule e nas folhas, para enfrentar o período seco. As espécies vegetais que habitam esta área são em geral dotadas de folhas pequenas, uma adaptação para reduzir a transpiração.

Através do trabalho conduzido por Pereira Júnior et al. (2016), em uma área semelhante, a vegetação pode ser classificada como arbustivo-arbórea. Com o levantamento fitossociológico pode determinar as espécies vegetais que predominam a área experimental. Já o levantamento das espécies existentes na área foi estimado pela a densidade das mesmas, levando em consideração o total de plantas que se encontravam em um hectare, sendo as mais frequentes as das famílias Fabaceae, com a maior riqueza florística, seguido da Euphorbiaceae, Mimosaceae e Combretaceae. Vale ressaltar que essas famílias juntas representam $54,5 \%$ das espécies registradas nessa pesquisa (Brasil, 2016).

Para a quantificação da serapilheira depositada sobre o solo da Caatinga, foram instaladas 20 caixas coletoras na área estudada, conforme metodologia apresentada por Souto (2006). Estas caixas foram construídas de madeira, com dimensões de $1,0 \mathrm{~m} \times 1,0 \mathrm{~m} \times 0,2 \mathrm{~m}$, com fundo em tela de náilon roxo com malha de $1 \mathrm{~mm}$, para drenagem da água da chuva, evitando assim início do processo de decomposição do material depositado (Figura 2). As caixas foram instaladas a uma altura de 0,20 $\mathrm{m}$ da superfície do solo, estas caixas foram distanciadas $30 \mathrm{~m}$ entre si, e a $10 \mathrm{~m}$ da margem do curso d'água.

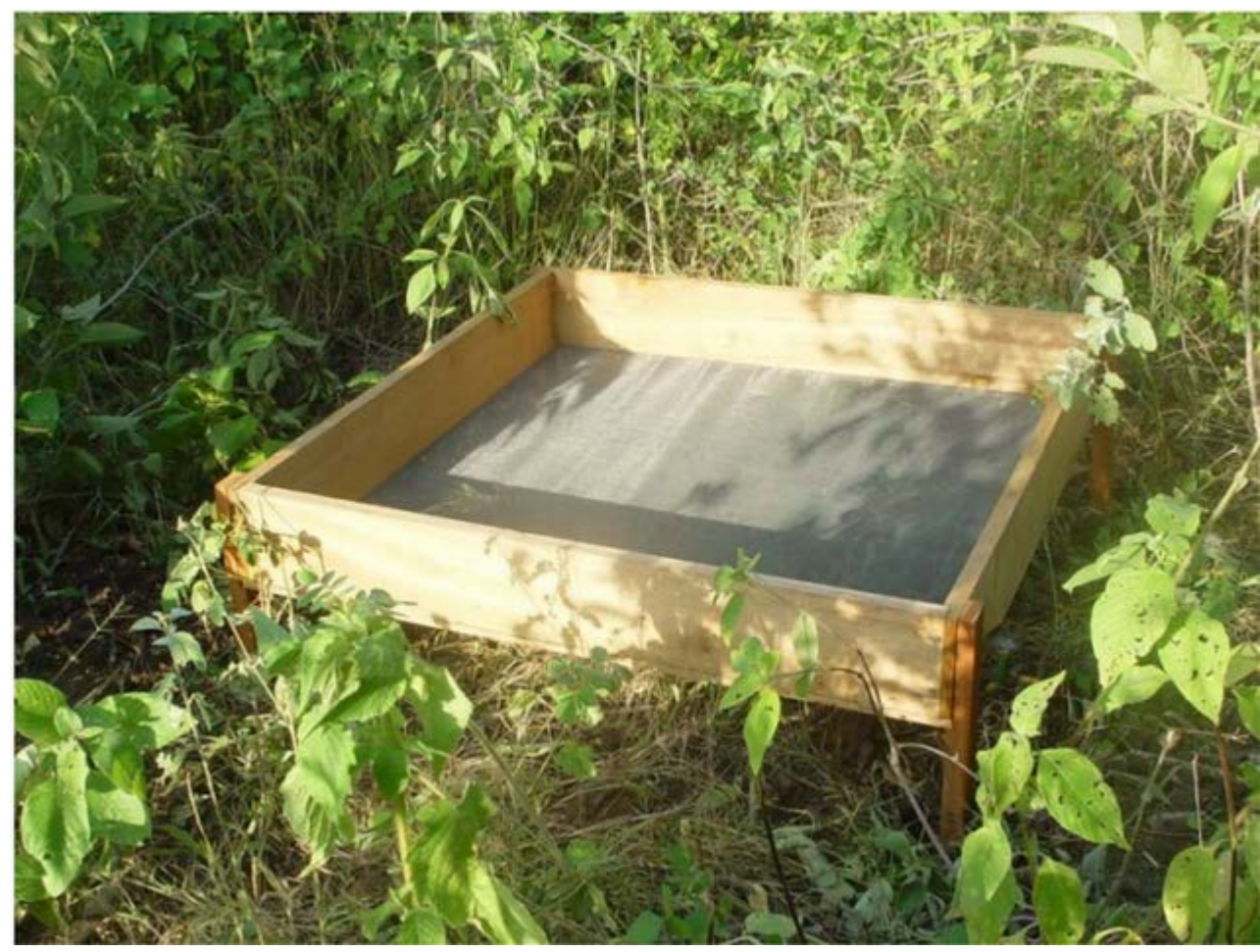

Figura 2. Modelo de caixa para coleta de serapilheira na microbacia estudada, Iguatu, Ceará, Brasil 


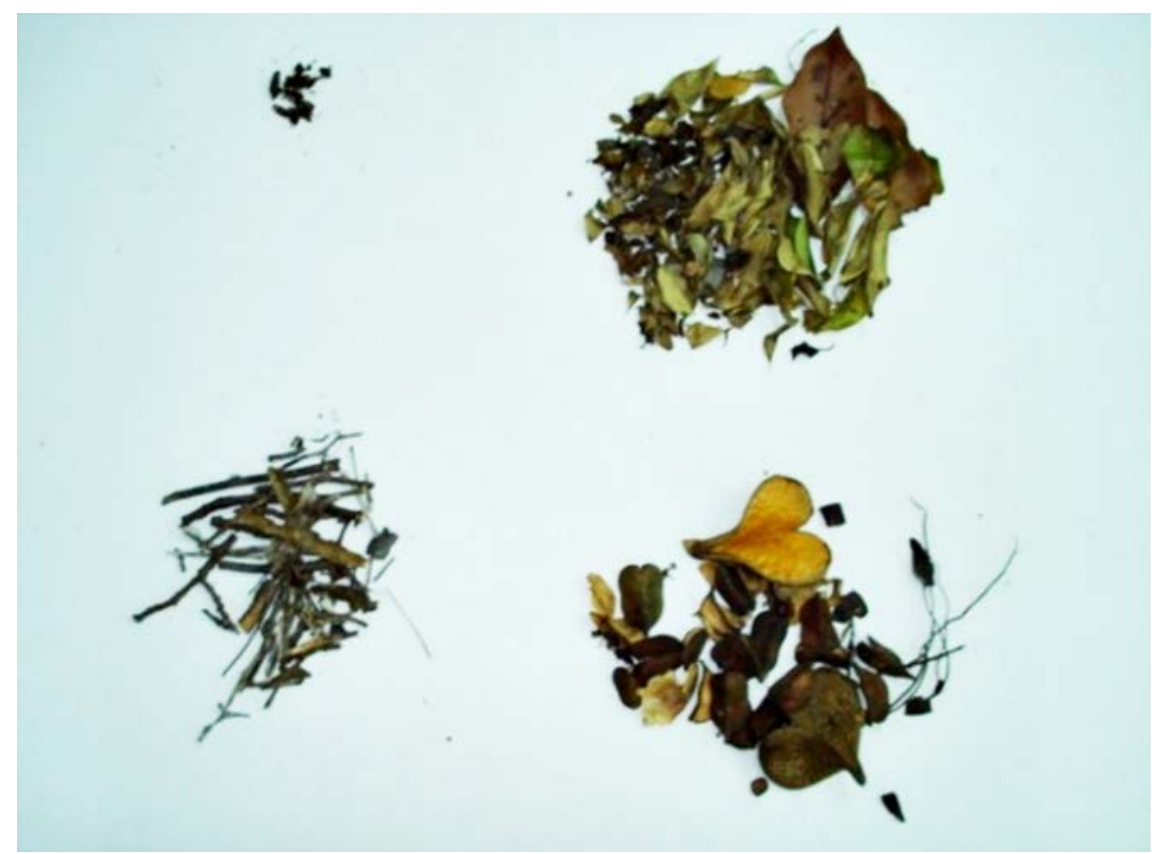

Figura 3. Separação das frações de folhas, galhos, estrutura reprodutiva e miscelânea da serapilheira, na microbacia estudada, Iguatu, Ceará, Brasil.

Mensalmente, durante o período de abril de 2013 a março de 2014, coletou-se o material depositado nas caixas, acondicionado em sacos de papel e levado ao Laboratório de Análises de Água, Solos e Tecidos Vegetal, LABAS do IFCE, Campus Iguatu, para em seguida ser separado nas frações: Folhas (incluindo pecíolos e folíolos), galhos (material lenhoso de todas as dimensões, além de cascas), estruturas reprodutivas (flores, frutos, restos de inflorescências e sementes) e miscelânea (materiais que não se conseguiu identificar e materiais de origem animal) (Figura 3).

\section{Resultados e discussão}

A precipitação pluviométrica total registrada na área de Caatinga conservada, no período de janeiro de 2013 a março de 2014, foi de $1.167,7 \mathrm{~mm}$. As chuvas da região se concentram nos primeiros meses do ano (Figura 4), definindo um período chuvoso que se concentrou nos meses de abril a junho 2013 e janeiro a março de 2014. Esta característica climatológica reflete diretamente na vegetação local e, consequentemente, na produção da fração folha e na época de deposição da serapilheira. Outro fator que deve ser considerado na produção de serapilheira em ambiente da caatinga além do total precipitado a cada ano, é a sua distribuição temporal, a qual terá forte influência no balanço hídrico da região.

A fração folhas mostrou-se em diferentes formas de comportamento, e teve seu maior pico registrado no mês de agosto de 2013 (Figura 4), atingindo uma produção de $1.268,57 \mathrm{~kg} \mathrm{ha}^{-1}$. Essa maior produção nesse mês está relacionada diretamente com a precipitação pluviométrica. Pois o período seco como pode observar, concentram-se nos meses de agosto, setembro e dezembro onde há falta de chuva na região. Silva et al. (2004), ressaltam as adaptações da Caatinga à condição de elevado déficit hídrico, em que as plantas depositam grandes quantidades de material decíduo para reduzir a transpiração. A menor deposição mensal da fração folhas foi verificada em dezembro de 2013, registrando uma produção de 26,03 $\mathrm{kg} \mathrm{ha}^{-1}$. Esse comportamento era esperado já que a quase totalidade das espécies da Caatinga apresentam aspecto caducifólio, e, portanto, perdem as folhas na época seca do ano. 
A produção da fração galhos apresentou-se em intensidades diferentes ao longo dos meses de estudo, e teve seu maior pico registrado no mês de maio de 2013 (Figura 5), atingindo uma produção de $142,00 \mathrm{~kg} \mathrm{ha}^{-1}$. A fração galhos totalizou $332,97 \mathrm{~kg} \mathrm{ha}^{-1}$ de toda a serapilheira produzida no primeiro ano (Tabela 2). Esses resultados assemelham-se aos encontrados por Santana (2005) e diferenciam-se dos observados por Souto (2006) e Costa et al. (2007). Fernandes e Scaramuzza (2007) citam que comparações entre estudos dessa fração têm sido dificultadas por não haver uma padronização quantos às dimensões, ao contrário da fração folhas, o que tem levado a resultados aparentemente contraditórios. A menor deposição mensal da fração galhos foi verificada em outubro de 2013, registrando uma produção de $27,87 \mathrm{~kg} \mathrm{ha}^{-1}$. De uma maneira geral, observa-se uma redução na deposição dessa fração à medida que se encerra a quadra chuvosa e durante a época seca do ano, vindo a aumentar com o avanço da nova quadra chuvosa.

A produção da fração estrutura reprodutiva apresentou-se em intensidades diferentes ao longo dos meses de estudo, e teve seu maior pico registrado no mês de março de 2014 (Figura 6), atingindo uma produção de $134,26 \mathrm{~kg} \mathrm{ha}^{-1}$. Isso está relacionado diretamente com a precipitação pluviométrica, pois com as chuvas contínuas, e quando começa a produzir as estruturas reprodutivas. As estruturas reprodutivas respondem por 46,4\% (289,35 $\mathrm{kg} \mathrm{ha}^{-1}$ ) da serapilheira total produzida nesses meses estudo (Tabela 2). Esses resultados assemelham-se aos observados por Costa et al. (2007) e Souto (2006), nesse mesmo bioma. Observa-se uma produção ininterrupta dessa fração, com baixos valores na época seca e aumentos substanciais a partir do início da quadra chuvosa. A menor deposição mensal da fração estrutura reprodutiva foi observada no mês de junho de 2013 com apenas
$3,48 \mathrm{~kg} \mathrm{ha}^{-1}$. Isso está relacionado com a diminuição das precipitações, já que quando começa as chuvas o sistema reprodutor evolui consideravelmente.

A fração miscelânea (Figura 7) apresentou a menor participação da serapilheira produzida nesses meses de estudo, teve seu maior pico registrado no mês de maio de 2013 com uma produção de $125,27 \mathrm{~kg} \mathrm{ha}^{-1}$. A produção dessa fração se fez presente em todos os meses deste estudo, com leve tendência de aumento de deposição iniciando no meio da quadra chuvosa e se prolongando até a transição com a estação seca. Souto (2006) cita que a maior oferta de alimento para os insetos e pássaros nessa época, pode contribuir para uma maior deposição de fezes e partes de insetos mortos. Apesar da pequena participação na serapilheira total, a fração miscelânea tem importância considerável. Proctor (1987) considera que os componentes da miscelânea são ricos em nutrientes e energia e, associados ao alto grau de fragmentação, podem ser uma fonte mais acessível aos decompositores. A menor deposição mensal da fração miscelânea foi verificada no mês de agosto de 2013, registrando uma produção de 1,39 $\mathrm{kg} \mathrm{ha}^{-1}$.

Observou-se ainda na Tabela 2 que durante esses meses de estudo, abril de 2013 a março de 2014 a produção da serapilheira total foi de $4.038,79 \mathrm{~kg} \mathrm{ha}^{-1}$. Já a precipitação pluviométrica nesses meses estudados foi de 983,35 mm. Analisando-se ainda as frações estudadas: estrutura reprodutiva, folhas, galhos e miscelânea, a maior produção foi da fração folhas seguida por galhos, estruturas reprodutivas e miscelânea respectivamente. Isso pode ser explicado pelos períodos secos e chuvosos, pois cada fração irá dar respostas diferentes conforme as suas características. Como por exemplo, a fração folhas seu maior pico foi registrado no período seco logo após a quadra chuvosa. 


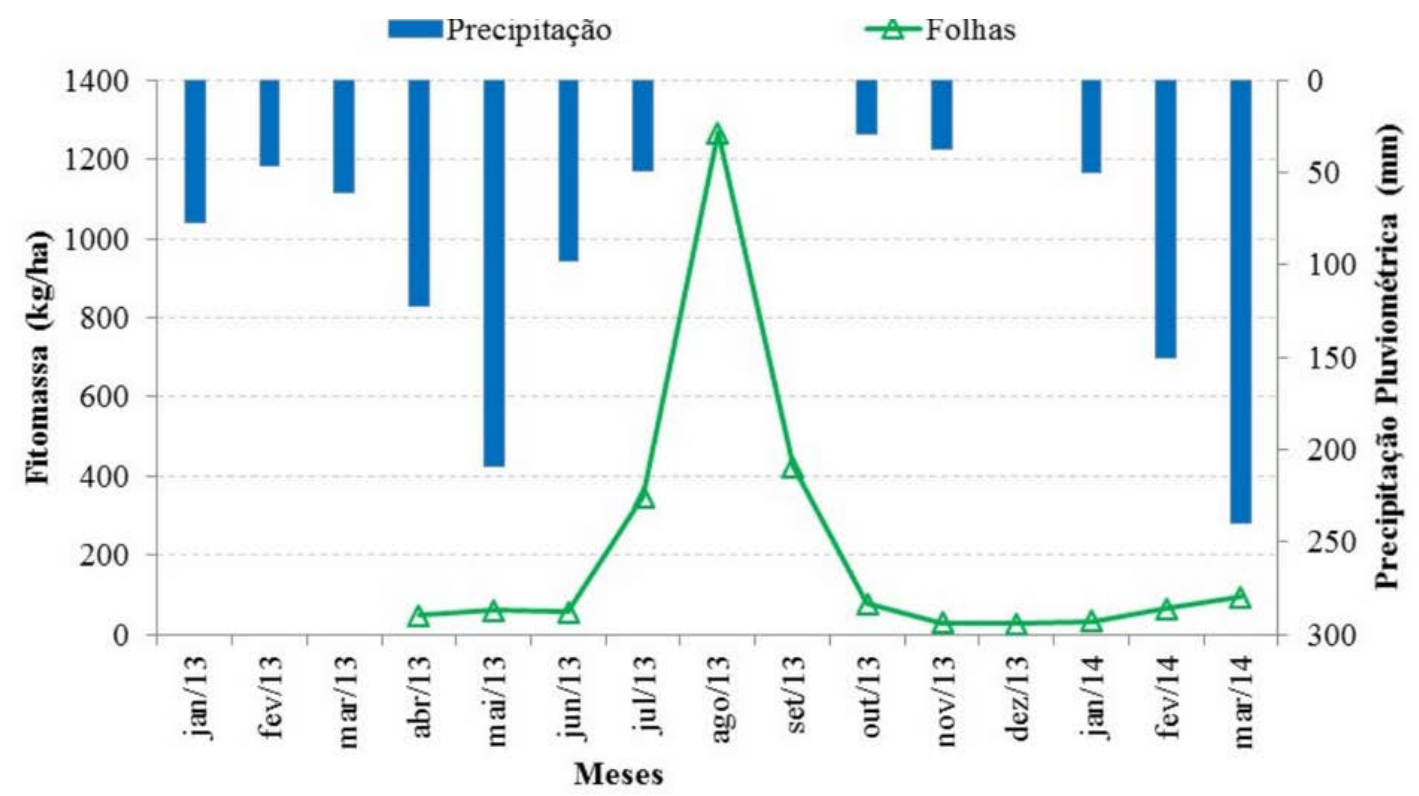

Figura 4. Precipitação pluviométrica e variação da fração folhas em área de Caatinga em Iguatu, Ceará.

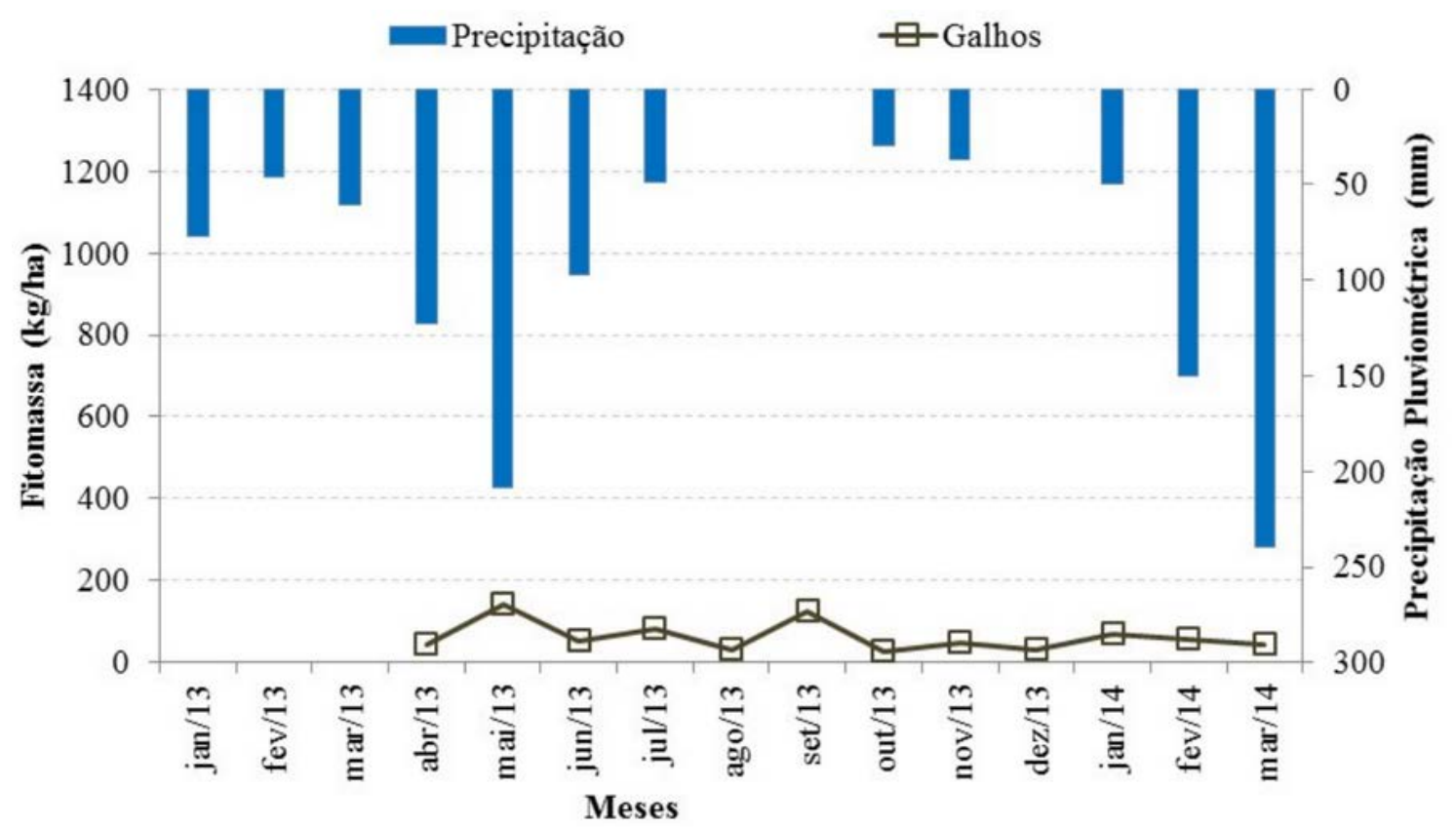

Figura 5. Precipitação pluviométrica e variação da fração galhos em área de Caatinga em Iguatu, Ceará. 
Tabela 2. Produção mensal e total dos percentuais de deposição de cada fração da serapilheira em área de Caatinga conservada.

\begin{tabular}{lcccccc}
\hline Mês & $\begin{array}{c}\text { Precipitação } \\
\text { (mm) }\end{array}$ & $\begin{array}{c}\text { Serapilheira } \\
\text { Total } \\
\mathbf{( k g . h a}^{-1} \mathbf{)}\end{array}$ & $\begin{array}{c}\text { Est. } \\
\text { Reprodutiva } \\
\mathbf{( \% )}\end{array}$ & $\begin{array}{c}\text { Folhas } \\
\mathbf{( \% )}\end{array}$ & Galhos & Miscelânea \\
\hline abr/13 & 122,38 & 120,72 & 20,15 & 39,19 & 37,09 & 3,57 \\
maio/13 & 208,75 & 332,97 & 1,73 & 18,00 & 42,65 & 37,62 \\
jun/13 & 97,50 & 117,80 & 2,95 & 48,27 & 44,47 & 4,30 \\
jul/13 & 48,63 & 456,21 & 2,18 & 76,20 & 18,21 & 3,42 \\
ago/13 & 0,00 & $1.310,25$ & 0,58 & 96,82 & 2,49 & 0,11 \\
set/13 & 0,00 & 602,68 & 6,40 & 70,30 & 20,90 & 2,40 \\
out/13 & 29,13 & 254,23 & 35,00 & 30,92 & 10,96 & 23,12 \\
nov/13 & 36,88 & 147,12 & 44,03 & 19,60 & 32,88 & 3,49 \\
dez/13 & 0,00 & 93,76 & 26,72 & 27,76 & 33,74 & 11,79 \\
jan/14 & 49,98 & 118,99 & 8,73 & 28,40 & 59,48 & 3,39 \\
fev/14 & 150,38 & 194,71 & 27,74 & 33,01 & 29,13 & 10,12 \\
mar/14 & 239,75 & 289,35 & 46,40 & 32,70 & 15,51 & 5,38 \\
\hline \multicolumn{1}{c}{ Total } & 983,35 & $4.038,79$ & - & - & - & - \\
\hline
\end{tabular}

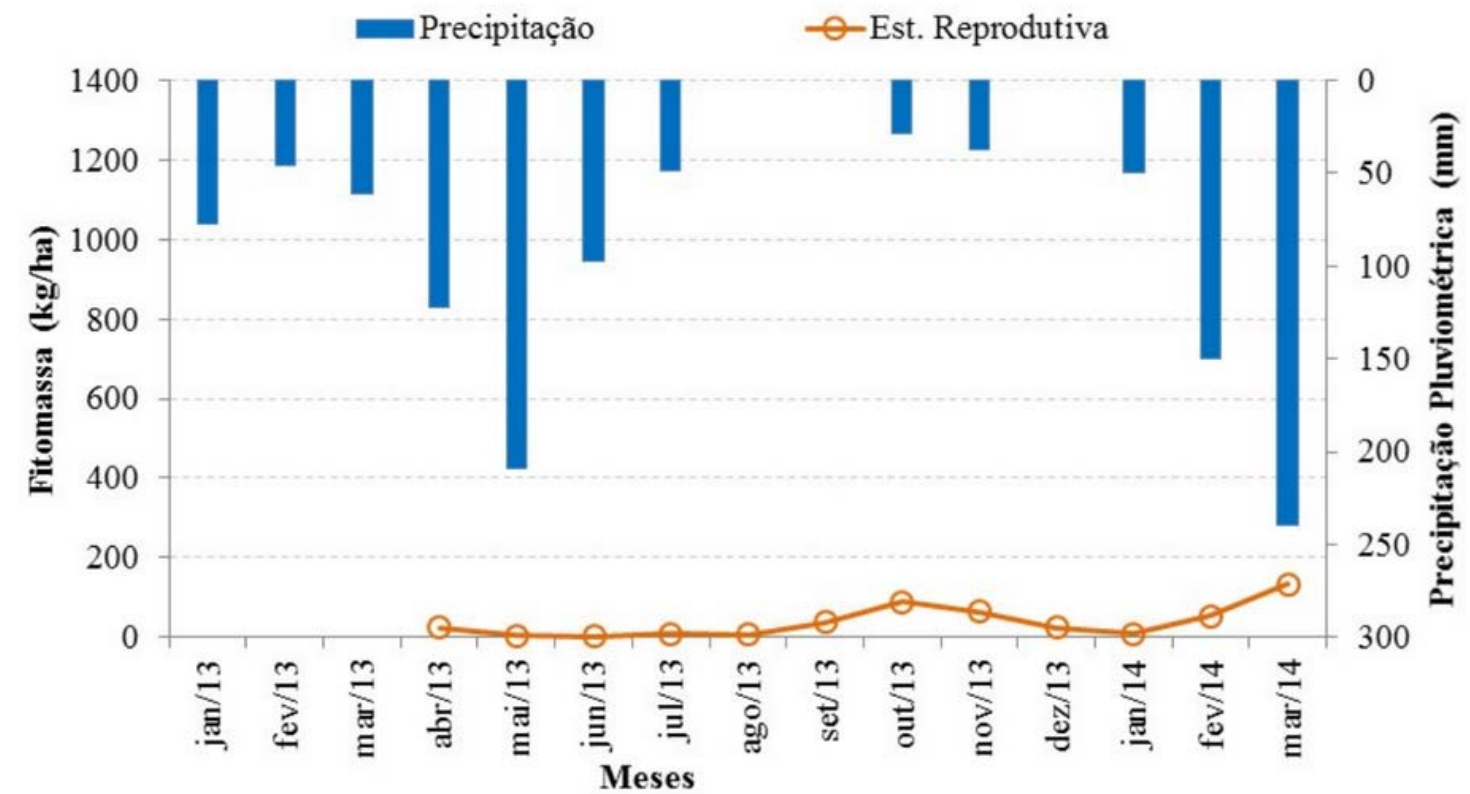

Figura 6. Precipitação pluviométrica e variação da fração Estação Reprodutiva em área de Caatinga em Iguatu, Ceará. 


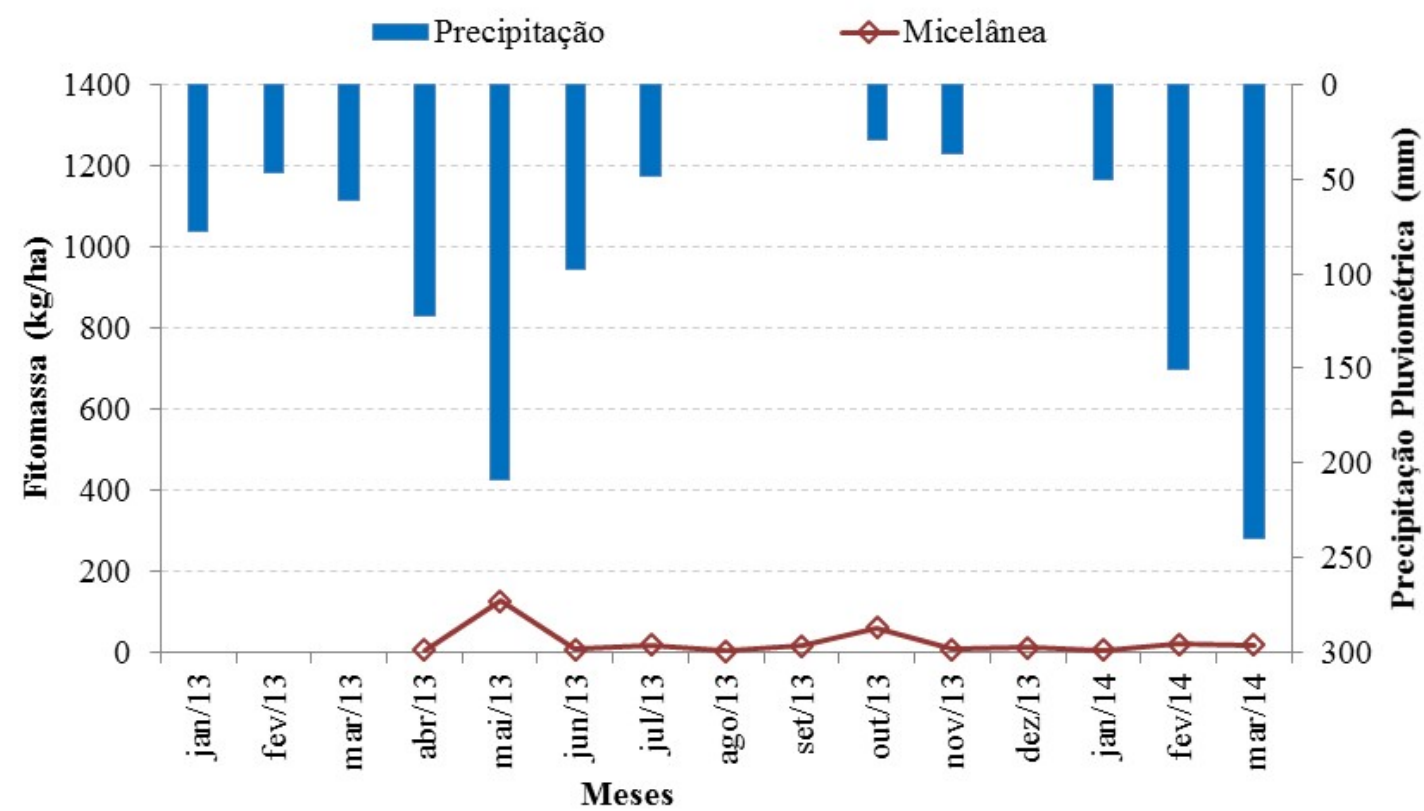

Figura 7. Precipitação pluviométrica e variação da fração miscelânea em área de Caatinga em Iguatu, Ceará.

\section{Conclusões}

O estudo demonstra a importância da produtividade do bioma caatinga, que é altamente dependente da diversidade de espécies presentes. A produção de serapilheira de folhas apresenta uma total relação com o regime pluviométrico, sendo seu ápice de produção logo após a quadra chuvosa; enquanto a produção de estruturas reprodutivas é determinada pelas espécies. Já a fração galhos observa-se uma redução na deposição dessa fração à medida que se encerra a quadra chuvosa e durante a época seca do ano, vindo a aumentar com o avanço da nova quadra chuvosa. E por último a fração miscelânea que se fez presente em todos os meses deste estudo, com leve tendência de aumento de deposição iniciando no meio da quadra chuvosa e se prolongando até a transição com a estação seca. A produção de serapilheira total apresenta caráter sazonal, com picos de produção imediatamente posterior a quadra chuvosa.

\section{Agradecimentos}

Fundação Cearense de Apoio ao Desenvolvimento Científico e Tecnológico (FUNCAP), pela bolsa concebida.

\section{Declaração de conflito de interesses}

Os autores declaram não haver conflitos de interesses.

\section{Referências}

Alves, A. R.; Souto, J. S.; Souto, P. C.; Holanda, A. C. Aporte e decomposição de serrapilheira em área de Caatinga, na Paraíba. Revista de Biologia e Ciências da Terra, v. 6 , n. 2, p. 194-203, 2006.

Brasil, J. B. Influência da sazonalidade e características das chuvas na interceptação em área de caatinga no semiárido. Iguatu: Instituto Federal de Educação, Ciência e Tecnologia do Ceará, 2016. (Monografia). 
Costa, C. C. A.; Dantas, I. M.; Camacho, R. G. V.; Souza, A. M.; Silva, N. F. Produção de serapilheira na Caatinga da Floresta Nacional do Açu-RN. Revista Brasileira de Biociências, v. 5, n. S1, p. 246-248, 2007.

Facelli, J. M.; Pickett, S. T. A. Plant litter: its dynamics and effects on plant Community structure. The Botanical Rewiew, v. 57, p. 1-32, 1991. http://dx.doi.org/10.1007/BF02858763

Fernandes, F. C. S.; Scaramuzza, W. L. M. P. Produção e decomposição da liteira em fragmento florestal em Campo Verde (MT). Revista de Ciências Agrárias, v. 47, n. 1, p. 173-186, 2007.

Ferreira, R. L. C.; Lira Junior, M. A.; Rocha, M. S.; Santos, M. V. F.; Lira, M. A.; Barreto, L. P. Deposição e acúmulo de matérias secas e nutrientes em serapilheira em um bosque de sabiá (Mimosa caesalpiniifolia Benth.). Revista Árvore, v. 31, n. 1, p. 7-12, 2007.

Funceme - Fundação Cearense de Meteorologia e Recursos Hídricos. 2012. Disponível em: $<$ http://www.funceme.br/>. Acesso em: 04 mar. 2016.

MMA - Ministério do Meio Ambiente. Caatinga. Disponível em: $<$ http://www.mma.gov.br/biomas/caatinga $>$.

Acesso em: 10 nov. 2014.

Pereira Júnior, L. R.; Andrade, E. M.; Palácio, H. A. Q.; Raymer, P. C. L.; Ribeiro Filho, J. C.; Pereira, F. J. S. Carbon stocks in a tropical dry forest in Brazil. Revista Ciência Agronômica, v. 47, n. 1, p. 32-40, 2016.

Pinheiro, A. G. Eficiência da cobertura com Andropogon gayanus (Kunt) nas perdas de água e solo no semiárido. Iguatu: Instituto
Federal de Educação, Ciência e Tecnologia do Ceará, 2015. (Monografia).

Proctor, J. Nutrient cycling in primary and old secondary forest. Applied Geography, v. 7, n. 2, $\quad$ p. 135-152, 1987. http://dx.doi.org/10.1016/0143-6228

Santana, J. A. S. Estrutura fitossociológica, produção de serapilheira e ciclagem de nutrientes em uma área de Caatinga no Seridó do Rio Grande do Norte. Areia: Universidade Federal da Paraíba, 2005. (Tese de doutorado).

Santos, J. C. N. Mensuração da erosão do solo no semiárido em diferentes usos de terras e escalas espaciais. Fortaleza: Universidade Federal do Ceará, 2012. (Dissertação de mestrado).

Silva, E. D.; Nogueira, R. J. M. C.; Azevedo Neto, A. D.; Brito, J. Z.; Cabral, E. L. Aspectos ecofisiológicos de dez espécies em uma área de Caatinga no Município de Cabaceiras, Paraíba, Brasil. Iheringia, Série Botânica, v. 59, n. 2, p. 201-205, 2004. Disponível em: <http://www.fzb.rs.gov.br/upload/20140328140 744ih59_2_p201_206.pdf $>$. Acesso em: 04 mar. 2016.

Souto, P. C. Acumulação e decomposição da serapilheira e distribuição de organismos edáficos em área de Caatinga na Paraíba. Areia: Universidade Federal da Paraíba, 2006. (Tese de doutorado)

Vital, A. R. T.; Guerrini, I. A.; Franken, W. K.; Fonseca, R. C. B. Produção de serapilheira e ciclagem de nutrientes de uma Floresta Estacional semidecidual em zona ripária. Revista Árvore, v. 28, n. 6, p. 793-800, 2004.

Informação da Licença: Este é um artigo Open Access distribuído sob os termos da Licença Creative Commons AtribuiçãoSemDerivações-SemDerivados, que permite o download do trabalho e o compartilhamento desde que seja atribuído o devido crédito, mas sem que possa ser alterado de nenhuma forma ou utilizá-los para fins comerciais. 